\title{
Determining Gender of Flushing American Woodcock (Scolopax minor)
}

\author{
E. FRANK BOWERS, ${ }^{1,2}$ Retired U.S. Fish and Wildlife Service, Southeast Region, Atlanta, Georgia 30345, USA
}

\begin{abstract}
I investigated the possibility of determining gender of flushed American woodcock (Scolopax minor) by using flush and flight behavior occurring in the first 9-11 $\mathrm{m}$ of an initial flush. Correct gender predictions of flushing birds could provide an option for hunters to voluntarily modify their harvest. During 2013-2015, I harvested 130 woodcock and found that most females ( $>75 \%$ on initial flush) reached greater heights $(>3 \mathrm{~m})$ than males in the first $9-11 \mathrm{~m}$ of the first flush. Such tower-flush behavior was not common for males, who instead flushed more horizontally than vertically, appeared smaller, and flew in a more twisting manner than females.
\end{abstract}

In 2017, I verified my gender assignment method and found that I could identify the higher, tower-flushing females $>63 \%$ of the time before deciding to shoot. Using the tower-flushing behavior method, woodcock hunters have an option to reduce female harvest, possibly resulting in more breeding females returning to breed the following season. Four conditions and situations that could prompt hunters to exercise limited harvest of females include: (1) whenever one or two females have been bagged that day, (2) the hunt area is saturated with woodcock, (3) the hunt site will be hunted numerous times in a season, and (4) hunters wanting to improve their ability to recognize flushed females.

Proceedings of the American Woodcock Symposium 11: 264

KEY WORDS: American woodcock, gender assignment, hunter selection

1 email: fbowers1942@att.net

2 present address: 3262 Allen Cir., Loganville, GA 30052 USA 